\title{
Ti-15Mo alloy prepared by cryogenic milling and spark plasma sintering
}

\author{
A. Terynkováa , J. Kozlík ${ }^{\mathrm{a}}$, K. Bartha ${ }^{\mathrm{a}}$, T. Chráska ${ }^{\mathrm{b}}$, J. Stráskýa $^{\mathrm{a}}$ \\ ${ }^{a}$ Department of Physics of Materials, Charles University, Ke Karlovu 5, 12116 Prague, Czech Republic \\ ${ }^{b}$ Institute of Plasma Physics, Czech Academy of Sciences, Za Slovankou 1782/3, 18200 Prague, Czech Republic \\ *annaterynkova@gmail.com
}

In this study, Ti-15Mo alloy powder was prepared by gas atomization and subsequent cryogenic milling in order to achieve ultra-fine grained microstructure. Both milled and non-milled powders were compacted by spark plasma sintering (SPS) at temperature of $800{ }^{\circ} \mathrm{C}$ for different sintering times up to 6 minutes. Sintering temperature and time affect porosity, microstructure and phase composition of the alloy. Milled powder can be sintered at comparatively lower temperature to achieve fully dense material. Sintering below $\beta$-transus temperature results in $\alpha+\beta$-structure. Furthermore, amount of $\alpha$-phase is higher in the material sintered from the milled powder due to increased oxygen content and also due to refined microstructure which facilitates $\alpha$-phase precipitation. Mechanical properties are also affected by formation of $\omega$-phase during uncontrolled cooling in the SPS machine.

\section{Introduction}

Titanium and its alloys are perspective for their unique properties such as low density, high strength or good biocompatibility in comparison with steels [1], [2]. They are nowadays commonly used in aircraft industry or in biomedicine. Fabrication of titanium alloys by powder metallurgy (PM) is currently a hot-topic as it is able to reduce production costs by possibility of near-net-shape processing. Another advantage of PM is possibility of alloys production by mechanical alloying [3]. Current research focuses mainly on additive manufacturing (3D printing) of the most common Ti alloy - Ti6Al4V alloy [4].

In this study we focus on a very different PM process of spark plasma sintering (SPS) which was applied for the first time on a metastable Ti-15Mo alloy. During SPS, the powder is heated by Joule heating of pulsed current directly at the point of contact of the individual powder particles. The times and temperatures required for compaction via SPS are therefore lower in comparison with other compaction methods such as conventional sintering.

Resulting microstructure of bulk material prepared by PM is also affected by size, shape and microstructure of powder particles, which can be affected by mechanical milling. In this study, cryogenic milling was utilized for processing Ti-15Mo alloy. Commercially pure $\mathrm{Ti}$ had been previously prepared by cryo-milling and it was found that particles fragmentation is not significant due to comparatively high ductility of Ti even at cryogenic temperatures; nevertheless powder particles are severely plastically deformed during milling [5]. Cryogenic temperatures then prevent dynamic recrystallization and grain growth and help to preserve ultra-fine grained microstructure.

Metastable $\beta$-Ti alloys replace Ti-6Al-4V alloy especially when very high strengths are required. Unlike $\alpha+\beta$-alloys, metastable $\beta$ Ti alloys do not undergo martensitic transformation when rapidly cooled from temperature above temperature of $\beta$-transus $\left(790^{\circ} \mathrm{C}\right.$ for Ti-15Mo alloy [6]). $\beta$-phase is therefore generally retained, despite $\omega_{\text {ath }}$ (athermal) forms upon quenching in comparatively less $\beta$-stabilized alloys [7]. Such quenched condition is referred to as a $\beta$-solution treated. Upon annealing at medium temperatures (usually around $500-750^{\circ} \mathrm{C}$ ) or during slow cooling from high temperatures, $\alpha$-phase precipitates. The shape, size and distribution of $\alpha$-phase particles depends on initial microstructure of parent $\beta$ matrix [8], [9]. $\alpha$-phase preferentially nucleates on $\beta / \beta$ grain boundaries, on dislocations or at particles of another phase (for instance $\omega$-phase particles) [10]. Small and homogenously distributed $\alpha$-phase particles are required to achieve maximum strength. $\alpha$-phase precipitation is accompanied by so-called element partitioning. Growing $\alpha$-phase expels $\beta$-stabilizing elements $(\mathrm{Mo}, \mathrm{V}, \mathrm{Nb})$ which are accumulated in surrounding $\beta$-matrix. Transfer of $\alpha$-stabilizing elements $(\mathrm{Al}, \mathrm{O}, \mathrm{N})$ is then in opposite direction [11], [12].

Another important factor affecting phase composition is contamination by oxygen and nitrogen, whose are $\alpha$-stabilizers and therefore increase temperature of $\beta$-transus and influence $\alpha$-phase precipitation [13].

In this work, a simple binary metastable $\beta$-Ti alloy Ti-15Mo was prepared by cryogenic milling (CM) of Ti-15Mo powder. Both initial and milled powders were subsequently compacted by spark plasma sintering (SPS) which was performed at $800^{\circ} \mathrm{C}$ for different sintering times up to 6 minutes.

\section{Experimental}

Ti-15Mo alloy was supplied in a form of rods by Carpenter Co and gas atomized on demand by TLS Technik GmbH \& Co. Spezialpulver KG, Germany. Initial powder particles were of size around $20 \mu \mathrm{m}$.

The initial powder was cryogenically milled in Union Process 01-HD attritor device in liquid argon using stainless steel balls with ball-to-powder ratio 16:1. The milling was performed for $4 \mathrm{~h}$ at milling speed of $700 \mathrm{RPM}$. $1.8 \mathrm{~g}$ of stearic acid was added to $180 \mathrm{~g}$ of Ti-15Mo powder as a process control agent. 
Spark plasma sintering (SPS) was performed in SPS 10-4 furnace made by Thermal Technology LLC, USA. The powder was sintered in a graphite die and the temperature was measured by a thermocouple placed in the bottom of the die, approx. 4 mm from the sintered powder. The powder was heated to temperature $750^{\circ} \mathrm{C}$ in 1 minute and subsequently heated up to $800^{\circ} \mathrm{C}$ with heating rate $100^{\circ} \mathrm{C} / \mathrm{min}$ (i.e. in $30 \mathrm{~s}$ ). This decrease of heating rate before reaching sintering temperature was employed to avoid temperature overshooting. After isothermal annealing at $800^{\circ} \mathrm{C}$ for selected sintering time (from 0 to 6 minutes), the sample was cooled down. The cooling was not actively controlled and cooling rate can be inferred from an example of temperature evolution for sintering time 1 min shown in Figure 1. The sintering pressure was $80 \mathrm{MPa}$. Sintering time of 0 minutes means that the sample was only heated up to the sintering temperature and immediately cooled.

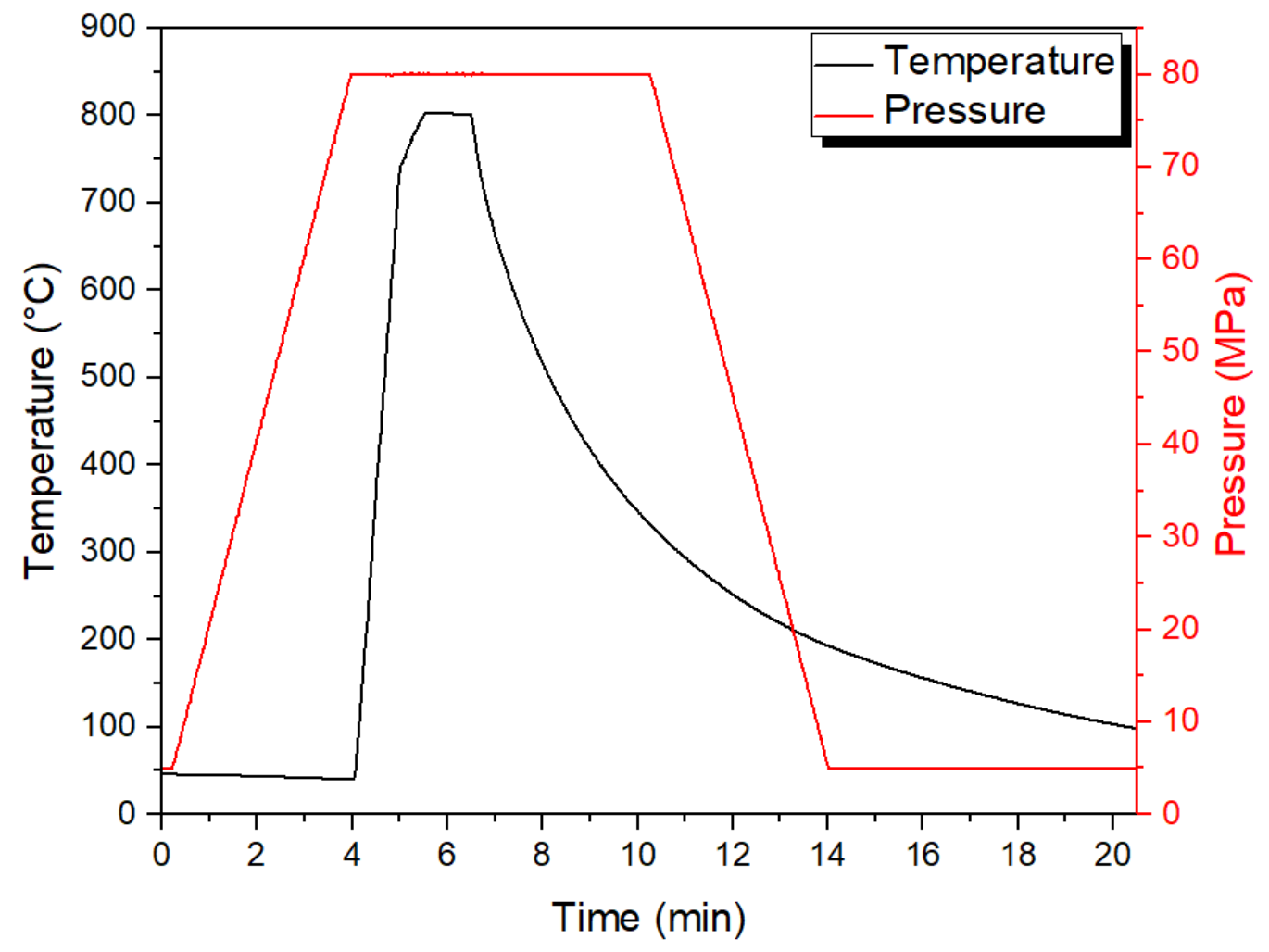

Figure 1: The development of temperature and pressure during sintering at $800^{\circ} \mathrm{C}$ for 1 minute

The resulting samples were produced in the shape of cylinder with the diameter of $20 \mathrm{~mm}$ and height of $7 \mathrm{~mm}$. Approx. $11 \mathrm{~g}$ of powder was used for each sample. Bulk sintered samples for microstructure observations and microhardness measurements were grinded on $\mathrm{SiC}$ papers and polished using three-step vibratory polisher. Sintered milled powders were further polished using Leica EM RES102 ion polisher. Initial and milled powders were just stuck on a conductive foil before observing in SEM.

Shape and size of powders and microstructure of bulk samples were studied by scanning electron microscope (SEM) FEI Quanta $200 \mathrm{~F}$ using accelerating voltage of $10 \mathrm{kV}$. Microhardness was measured using microhardness measurement device Qness Q10a by Vickers method with the load of $0.5 \mathrm{kgf}$.

Chemical contamination by gases was measured by carrier gas hot extraction (CGHE).

\section{Results}



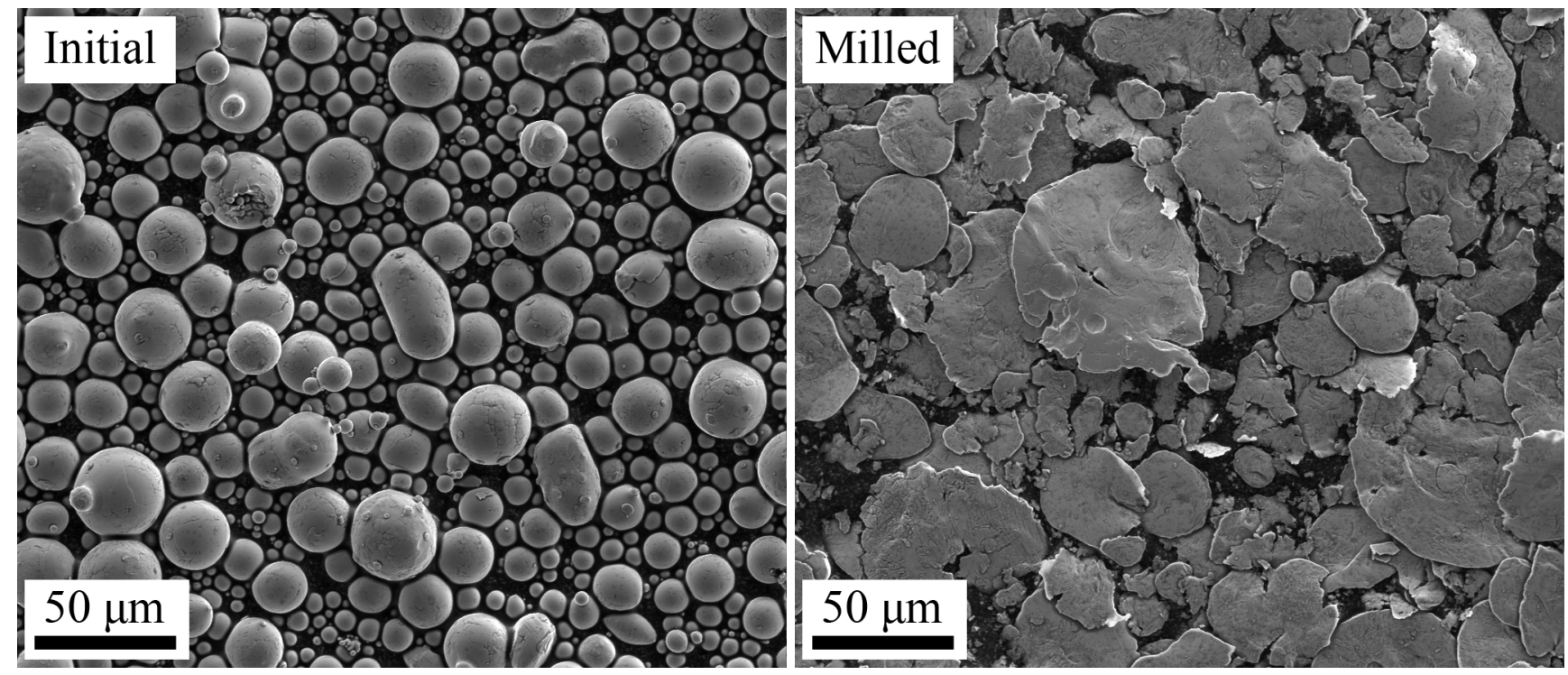

Figure 2: SEM micrographs using SE electron of initial and milled powder particles

Initial powder particles are displayed in Figure 2 left. Initial powder particles are in a shape of ball with size of around $20 \mu \mathrm{m}$. Milled powder particles (Figure 2 right) are in a shape of flat disks with diameter reaching $60 \mu \mathrm{m}$. Powder particles were not refined during milling but they were severely plastically deformed.

Table 1: Contamination of initial and milled powder by oxygen, hydrogen and nitrogen

\begin{tabular}{|c|c|c|c|}
\hline Powder & Oxygen & Hydrogen & Nitrogen \\
\hline Initial & 0.198 & $<0.001$ & 0.014 \\
\hline Milled & 0.784 & 0.147 & 0.030 \\
\hline
\end{tabular}

Chemical contamination of powder by oxygen, nitrogen and hydrogen significantly increases after milling.

SEM micrographs (secondary electrons) of material sintered from the initial powder for different sintering times are displayed in Figure 3. White spots in the images are impurities from polishing, whereas black spots correspond to pores. The quantity of pores decreases with increasing sintering time. In micrographs displaying samples sintered for 0,1 and 3 minutes, initial powder particles are recognizable due to pores surrounding them.
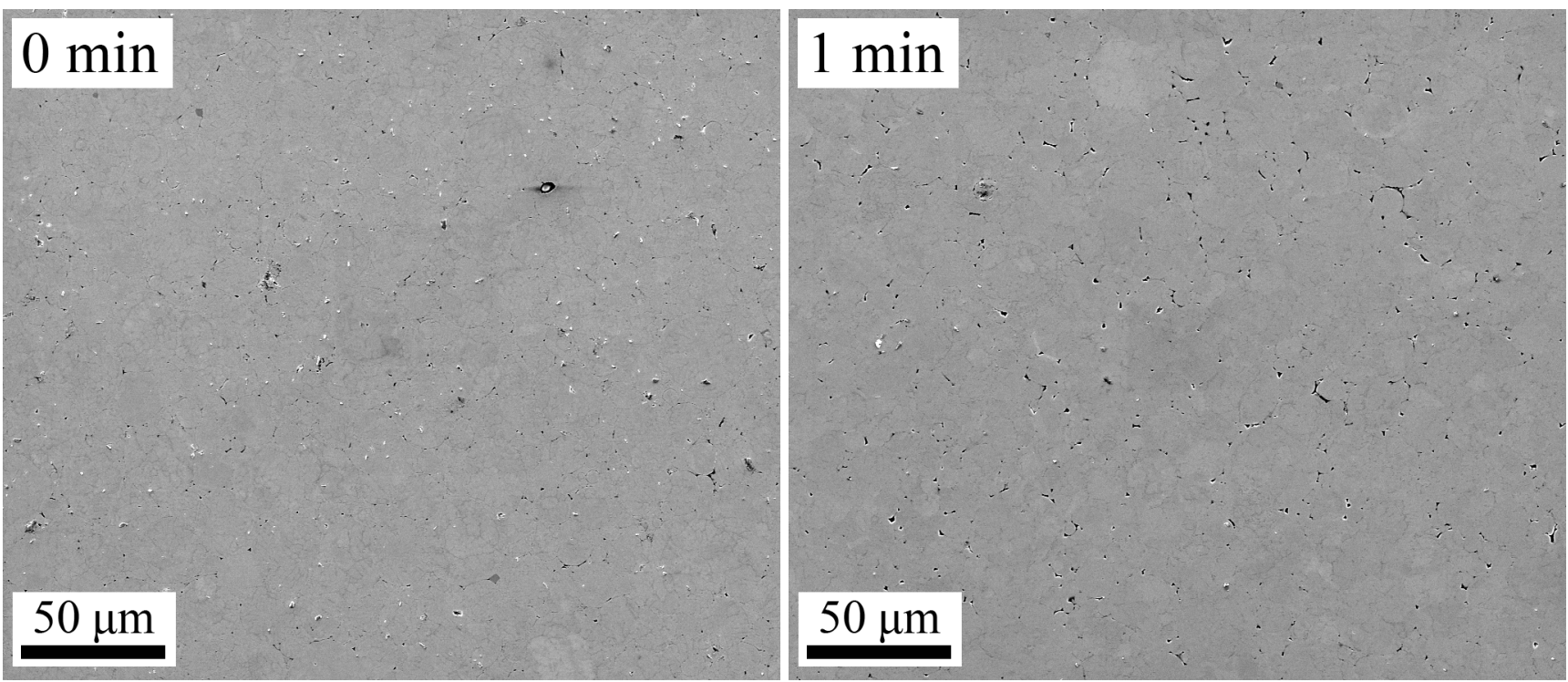


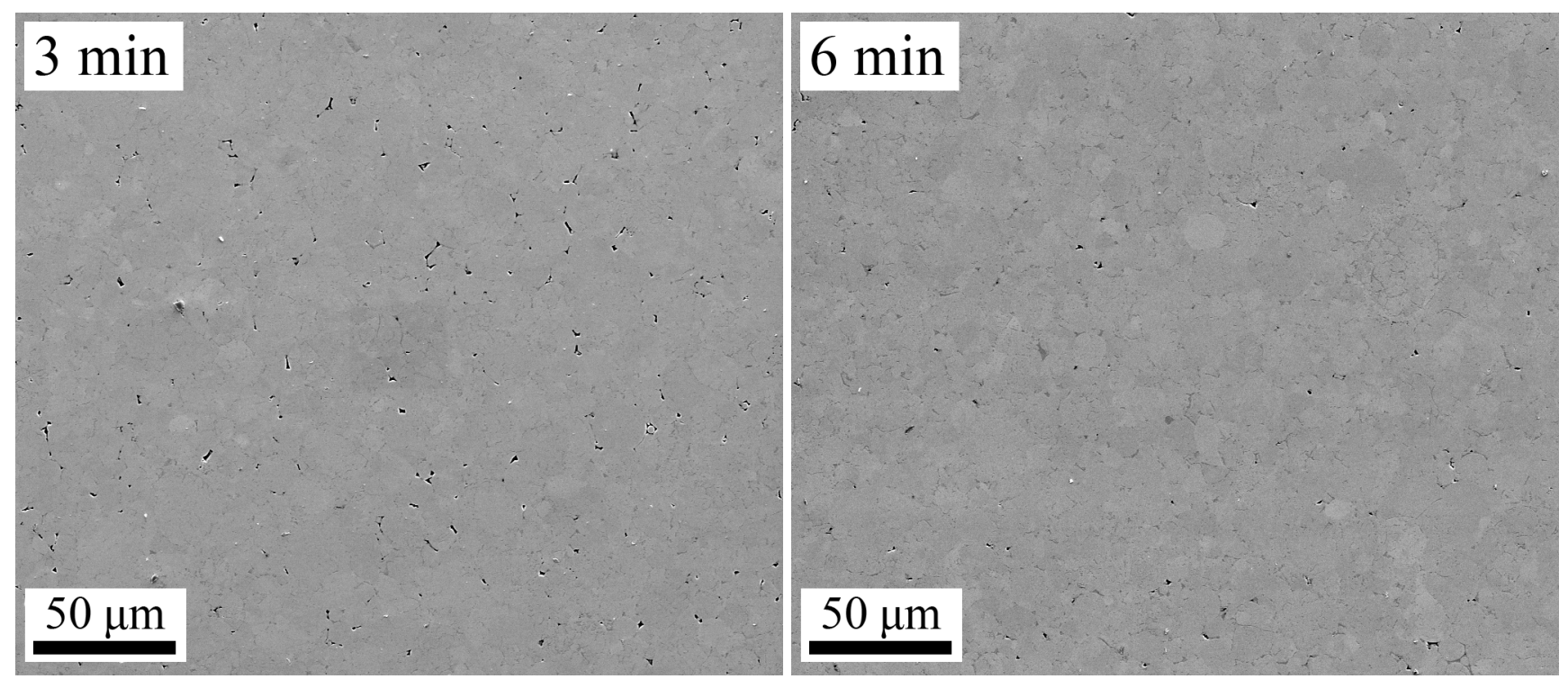

Figure 3: SEM micrographs using SE of initial powder sintered for $0,1,3$ and 6 minutes. Note that the white spots are artefacts from polishing and black dots correspond to pores.

Microstructure of samples sintered from milled powder at $0,1,3$ and 6 minutes is displayed in Figure 4. Besides white impurities from polishing and black pores, dimples created during ion polishing are also visible. The quantity of pores is significantly lower in comparison with the sintered initial powder. Milled powder is well sintered already after sintering for 0 minutes (i.e. after heating to $800{ }^{\circ} \mathrm{C}$ followed by immediate cooling).
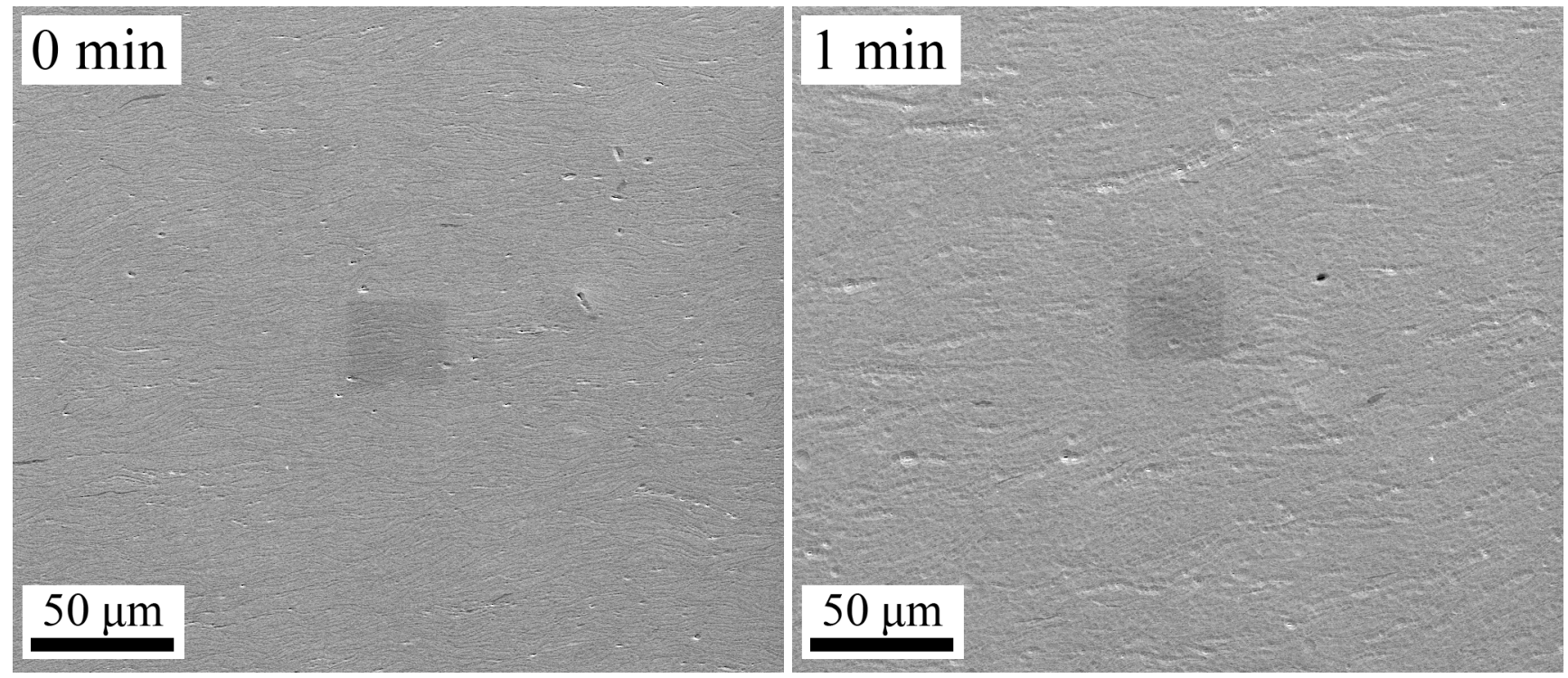

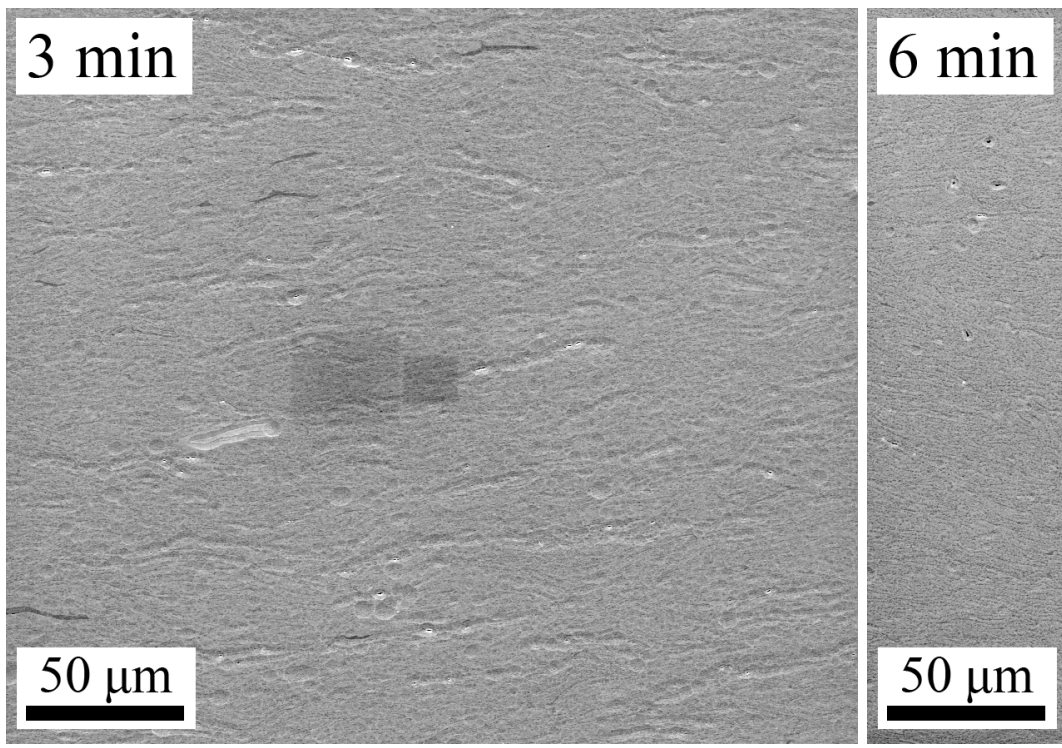

Figure 4: SEM micrographs using SE of milled powder sintered for $0,1,3$ and 6 minutes. Note that the white spots and dimples are artefacts from polishing and black dots correspond to pores. Dark rectangles are damaged areas by electron beam during previous SEM observations
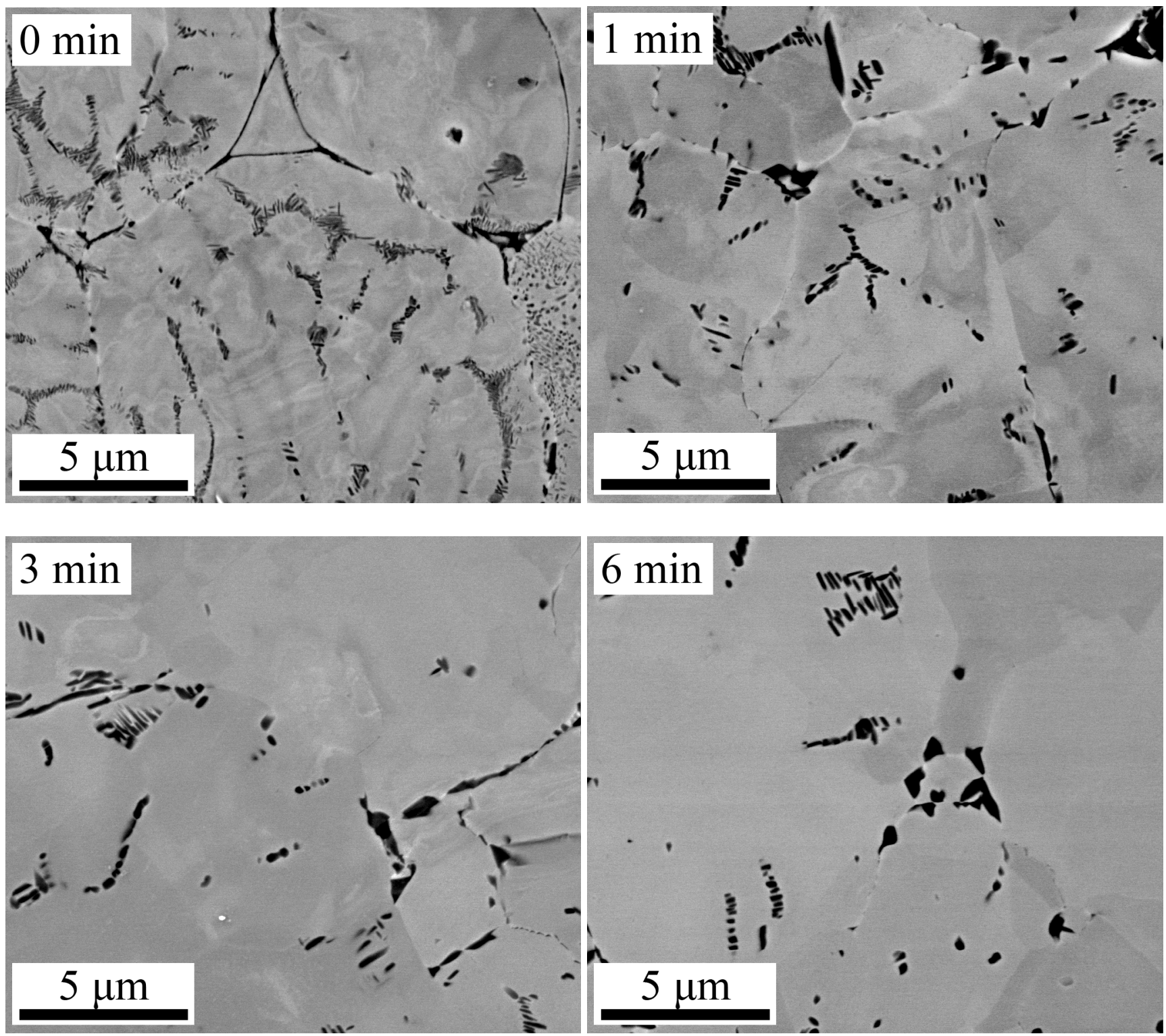
In detailed SEM micrographs of sintered initial powder in Figure 5, the microstructure and phase composition is displayed by channeling and chemical contrast, respectively. The amount of $\alpha$-phase which appears black due to lower content of heavier Mo atoms decreases with increasing sintering time. Simultaneously, $\alpha$-phase particles coarsen.

Microstructure and the amount of $\alpha$-phase of milled powder sintered for different times $(0,1,3,6 \mathrm{~min})$ are displayed in Figure 6 . The volume content of the $\alpha$-phase particles in the sintered milled powder is incomparably higher than in the sintered initial material. The amount of $\alpha$-phase particles is again decreasing with increasing sintering time while $\alpha$-particles are growing. The difference in particles size is the most distinctive between sintering for 0 and 1 minutes. On the other hand, between samples sintered for 3 and 6 minutes, the difference in the size of $\alpha$-phase particles is not significant.
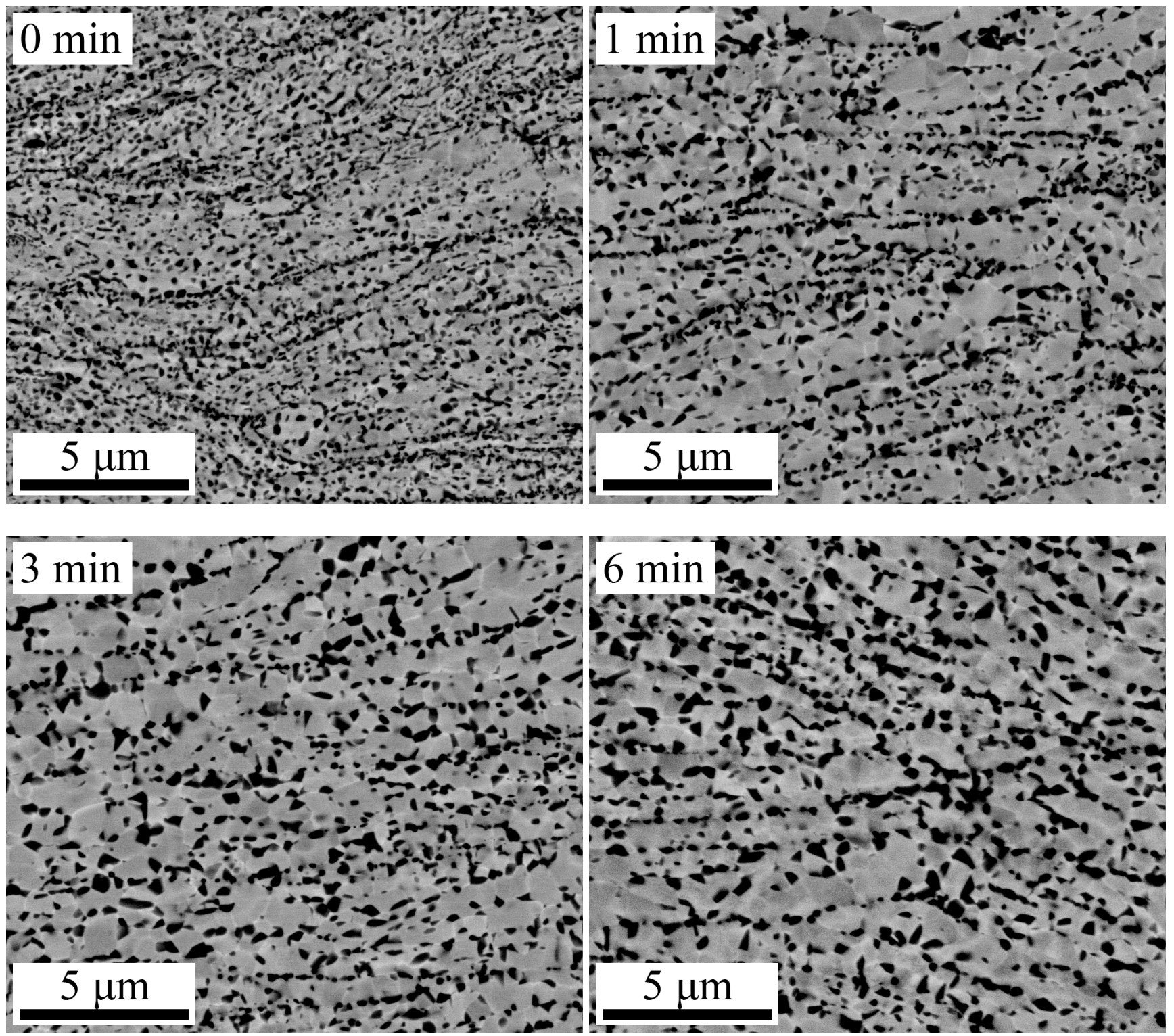

Figure 6: Detailed SEM micrograph using BSE of milled powder sintered for 0, 1, 3 and 6 minutes

The dependence of the microhardness on the sintering time of sintered initial and milled powders is shown in Figure 7 . While microhardness of sintered initial powder significantly increases with sintering time, microhardness of sintered milled powder slightly decreases with increasing sintering time. 


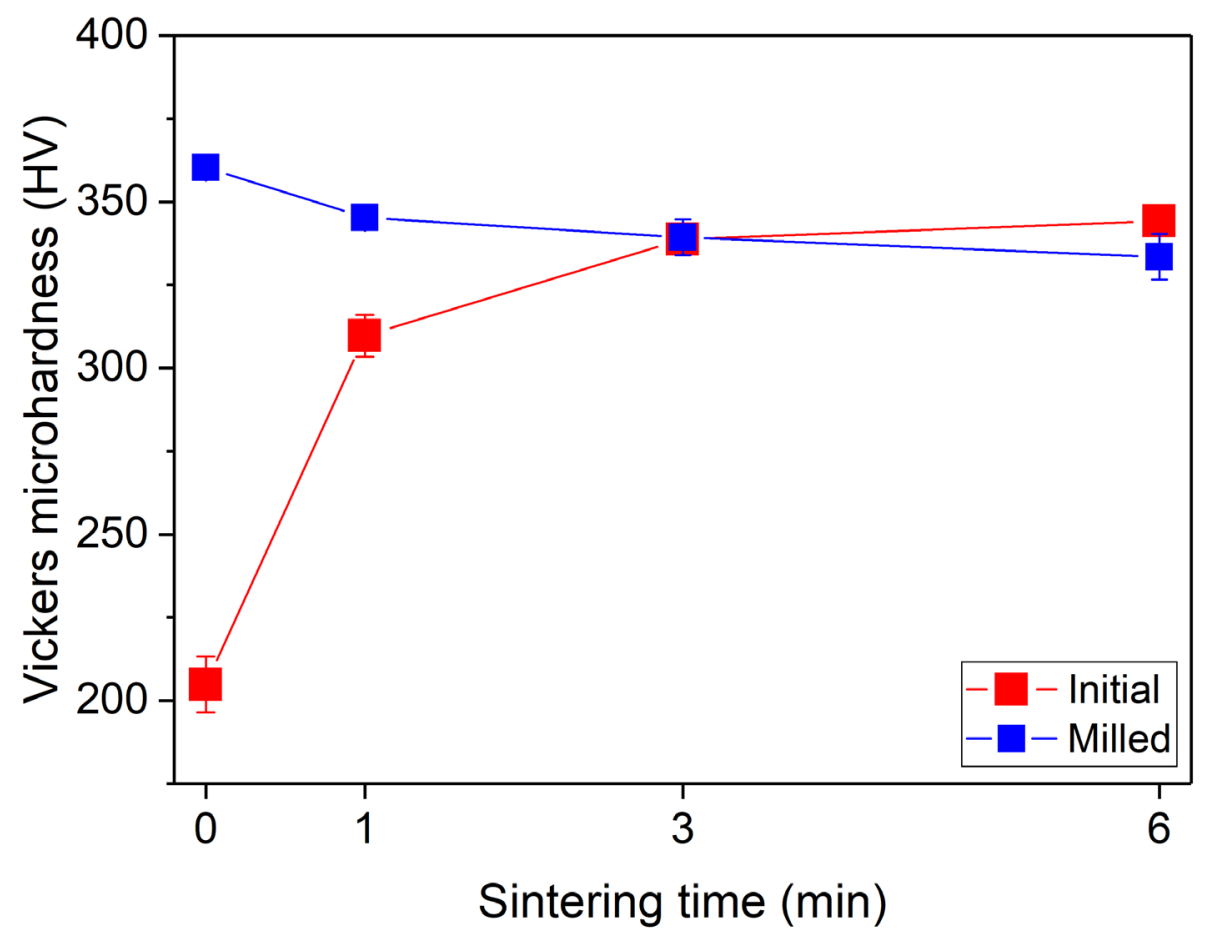

Figure 7: Microhardness of sintered initial and milled powder depending on the time of sintering

\section{Discussion}

Gas atomization of Ti-15Mo powder was successful and resulted in ball shaped particles of size around $20 \mu \mathrm{m}$. Powder particles were not refined by cryogenic milling due to high ductility of Ti-15Mo alloy even at low temperatures [5] but high deformation was inserted into the particles and the initially round powder particles were changed into disk-shaped particles.

The contamination of milled powder by oxygen, hydrogen and nitrogen is higher in comparison with initial powder despite the milling was performed in inert atmosphere of liquid argon. One of the reason is the stearic acid added to the powder before milling to prevent cold-welding. $1.8 \mathrm{~g}$ stearic acid added into $180 \mathrm{~g}$ of Ti-15Mo powder may cause maximum contamination of $0.113 \mathrm{wt}$. $\%$ by oxygen and maximum contamination of $0.127 \mathrm{wt} \%$ by hydrogen. Hydrogen contamination presented in Table 1 is in accordance with this calculation, however contamination by oxygen is significantly higher. Oxygen content may be increased by powder oxidation in the air - note that the total area of surface was significantly increased by milling. Oxygen can be also captured by liquid argon and contaminate the powder during milling.

The temperature of $\beta$-transus of Ti- $15 \mathrm{Mo}$ alloy is about $790^{\circ} \mathrm{C}[6]$ and therefore $\alpha$-phase should not precipitate during sintering at $800^{\circ} \mathrm{C}$. Cooling during SPS is not actively controlled - typical cooling rate can be derived from Figure 1, but it also depends on the time of sintering - the longer sintering time, the slowest cooling due to the graphic die being warmed more thoroughly. Temperature range critical for $\alpha$-phase precipitation is $750-500^{\circ} \mathrm{C}$ and time spent in this range is about $60-120 \mathrm{~s}$. $\omega$-phase forms at temperatures between 450 and $250^{\circ} \mathrm{C}$. Due to decreasing cooling rate, time spent in this temperature range is about $170-250 \mathrm{~s}$. These temperature ranges are valid for non-deformed material [7], [14], [15]. It is therefore assumed that $\alpha$-phase particles in the sintered initial powder precipitated during cooling from the sintering temperature. Preferential nucleation sites are grain boundaries, inter-particle boundaries and triple points. This behaviour is common also for bulk material [10].

Increased amount of $\alpha$-phase in the sintered milled powder can be reasoned by two different mechanisms. $\beta$-transus is significantly affected by chemical contamination by oxygen, which is a strong $\alpha$-stabilizer and cause an increase of temperature of $\beta$-transus [16], [17]. Contamination by oxygen is significantly higher for milled powder and therefore also temperature of $\beta$-transus is higher and $\alpha$-phase can precipitate during the sintering. Contamination by oxygen $0,7 \mathrm{wt} \%$ in pure titanium cause icrease in temperature of $\beta$-transus up to $100^{\circ} \mathrm{C}$ [17], [18]. Milled powder is significantly deformed and contains high amount of lattice defects. Recent results show that $\alpha$-phase precipitation is significantly enhanced in severely deformed materials [19].

Microhardness of sintered initial powder grows with increasing sintering temperature primarily due to decreasing porosity. The microstructure coarsening and decreasing amount of $\alpha$-phase has minor effect on the microhardness. The microhardness after sintering for 1 - 6 minutes is comparatively high and does not correspond to the microhardness of solution treated bulk material [14]. This can be explained by some amount of $\omega$-phase which forms during insufficiently fast cooling. The $\omega$-phase significantly increases microhardness [20].

Microhardness of sintered milled powder is high already after sintering for 0 minutes, because milled powder is already well compacted, fine grained, contains high volume fraction of small $\alpha$-phase particles and is also contaminated by oxygen which causes material strengthening [21]. Microstructure of parent $\beta$-matrix and $\alpha$-phase particles significantly coarsens with increasing sintering time, which causes a slight decrease in microhardness. Microhardness of sintered milled powder and sintered initial 
powder is comparable after sintering for 3 and 6 minutes, which is rather surprising. We argue that sintered milled material contains high volume fraction of $\alpha$-phase which expels Mo atoms and consequently stabilizes surrounding $\beta$-matrix. As the result. $\omega$-phase cannot form in the sintered milled powder. The effects of $\omega$-phase in sintered initial material are comparable to the strengthening in sintered milled powder. Maximum attained microhardness reached was about $360 \mathrm{HV}$ which is comparable to a non-deformed Ti-15Mo alloy in aged $\alpha+\beta$-condition.

\section{Conclusions}

- Cryogenic milling significantly changes shape of powder particles, but do not refine them.

- Spark plasma sintering of both initial and milled powder resulted in dense and fully compacted bulk material.

- Milled material after sintering contains significantly higher amount of $\alpha$-phase, which can be explained by contamination by $\alpha$-stabilizing oxygen during milling.

- The amount of $\alpha$-phase particles decreases with increasing sintering time and microstructure coarsens for both initial and milled powders.

- Microhardness is affected by many factors such as microstructure, phase composition and porosity.

- Maximum microhardness reached was about $360 \mathrm{HV}$ which is comparable to a non-deformed Ti-15Mo alloy in aged $\alpha+\beta-$ condition.

\section{Acknowledgement}

Financial support by Czech Science Foundation under project 17-20700Y is gratefully acknowledged. A.T. acknowledges the student project of Grant Agency of Charles University GAUK No. 20119.

\section{7. $\underline{\text { References }}$}

[1] G. Lütjering and J. C. Williams, Titanium. Berlin: Springer-Verlag, 2003.

[2] F. H. (Sam) Froes, '1.1 - Titanium for medical and dental applications-An introduction', in Titanium in Medical and Dental Applications, F. H. Froes and M. Qian, Eds. Woodhead Publishing, 2018, pp. 3-21.

[3] Z. Z. Fang et al., 'Powder metallurgy of titanium - past, present, and future', Int. Mater. Rev., vol. 63, no. 7, pp. 407459, Oct. 2018.

[4] B. Dutta and F. H. (Sam) Froes, 'The Additive Manufacturing (AM) of titanium alloys', Met. Powder Rep., vol. 72, no. 2, pp. 96-106, Mar. 2017.

[5] J. Kozlík, J. Stráský, P. Harcuba, I. Ibragimov, T. Chráska, and M. Janeček, 'Cryogenic Milling of Titanium Powder', Metals, vol. 8, no. 1, p. 31, Jan. 2018.

[6] J. Disegi, Implant Materials. Wrought Titanium -15\% Molybdenum. Synthes, 2009.

[7] P. Zháňal et al., 'Evolution of $\omega$ phase during heating of metastable $\beta$ titanium alloy Ti-15Mo', J. Mater. Sci., vol. 53, no. 1, pp. 837-845, Jan. 2018.

[8] K. Bartha et al., 'Inhomogeneous Precipitation of the $\alpha$-Phase in Ti15Mo Alloy Deformed by ECAP', Trans Tech Publ., no. 941 , pp. 1183-1188, 2018.

[9] K. Bartha, J. Stráský, P. Harcuba, I. Semenova, V. Polyakova, and M. Janeček, 'Heterogeneous Precipitation of the $\alpha-$ Phase in Ti15Mo Alloy Subjected to High Pressure Torsion', ACTA Phys. Pol. A, no. 134, pp. 790-793, 2018.

[10] J. Šmilauerová et al., 'Ageing response of sub-transus heat treated Ti-6.8Mo-4.5Fe-1.5Al alloy', J. Alloys Compd., vol. 724, pp. 373-380, Nov. 2017.

[11] S. L. Semiatin, S. L. Knisley, P. N. Fagin, D. R. Barker, and F. Zhang, 'Microstructure evolution during alpha-beta heat treatment of Ti-6Al-4V', Metall. Mater. Trans. A, vol. 34, no. 10, pp. 2377-2386, Oct. 2003.

[12] G. Welsch, R. Boyer, and E. W. Collings, Materials Properties Handbook: Titanium Alloys. ASM International, 1993.

[13] Z. Liu and G. Welsch, 'Effects of oxygen and heat treatment on the mechanical properties of alpha and beta titanium alloys', Metall. Trans. A, vol. 19, no. 3, pp. 527-542, Mar. 1988.

[14] K. Václavová et al., 'Microhardness and microstructure evolution of ultra-fine grained Ti-15Mo and TIMETAL LCB alloys prepared by high pressure torsion', Mater. Sci. Eng. A, vol. 682, pp. 220-228, Jan. 2017.

[15] P. Zhán̆al et al., 'Phase Transformations in Ti-15Mo Investigated by in situ Electrical Resistance', Acta Phys. Pol. A, vol. 128, no. 4, pp. 779-782, 2015. 
[16] J. Syarif, T. N. Rohmannudin, M. Z. Omar, Z. Sajuri, and S. Harjanto, 'Stability of the beta phase in Ti-Mo-Cr alloy fabricated by powder metallurgy', J. Min. Metall. Sect. B Metall., vol. 49, no. 3, pp. 285-292, 2013.

[17] Z. Guo, S. Malinov, and W. Sha, 'Modelling beta transus temperature of titanium alloys using artificial neural network', Comput. Mater. Sci., vol. 32, no. 1, pp. 1-12, Jan. 2005.

[18] J. L. Murray and H. A. Wriedt, 'The O-Ti (Oxygen-Titanium) system', J. Phase Equilibria, vol. 8, no. 2, pp. 148-165, Apr. 1987.

[19] K. Václavová et al., 'Ultra-fine grained microstructure of metastable beta Ti-15Mo alloy and its effects on the phase transformations', IOP Conf. Ser. Mater. Sci. Eng., vol. 194, no. 1, p. 012021 , May 2017.

[20] J. Gao, A. J. Knowles, D. Guan, and W. M. Rainforth, ' $\omega$ phase strengthened 1.2GPa metastable $\beta$ titanium alloy with high ductility', Scr. Mater., vol. 162, pp. 77-81, Mar. 2019.

[21] J. Stráský et al., 'Increasing strength of a biomedical Ti-Nb-Ta-Zr alloy by alloying with Fe, Si and O', J. Mech. Behav. Biomed. Mater., vol. 71, pp. 329-336, Jul. 2017. 